\title{
Pengembangan Kemandirian Pesantren Melalui Program Santripreneur
}

\author{
Toha Maksum ${ }^{1}$, Muh Barid Nizarudin Wajdi ${ }^{2}$ \\ ${ }^{1}$ STAI Darussalam Nganjuk \\ ${ }^{2}$ STAI Miftahul Ula Nganjuk \\ mahsuntoha81@gmail.com
}

\begin{abstract}
Islamic boarding schools are traditional Islamic educational institutions in Indonesia that have grown and developed several centuries ago. Islamic boarding schools, in fact, are potential institutions to move towards a people-based economy, as well as the strength they have. If the Ponpes are only spectators in the coming era, other micro-economic institutions may move towards progress. Therefore, a careful analysis is needed to strengthen this economic institution, so that it does not go wrong. This study aims to develop the independence of santri through the santriprenenur program. The study was conducted at the Miftahul Mubtadiin Krempyang Nganjuk Islamic Boarding School. In-depth interviews and non-participating observations were used in data collection. in an effort to ensure the validity of the research data. The results of the study indicate that the santripreneurship program can develop well, so that it can become one of the vital economic supports of Islamic boarding schools, which have an impact on society..
\end{abstract}

Keywords: Santriprenenur, program kemandirian, pesantren

\section{Pendahuluan}

Pesantren adalah lembaga pendidikan Islam tradisional di Indonesia yang sudah tumbuh dan berkembang beberapa abad yang lalu ${ }^{1}$. Kata pesantren berasal dari kata "santri", yang diberi awalan pe dan akhiran an menjadi pesantrian (pesantren) berarti tempat tinggal para santri, sedangkan santri adalah orang yang menuntut ilmu agama Islam² ${ }^{2}$ Pesantren di Jawa dan Madura sering disebut dengan Pondok. Sementara itu, di Aceh corak pendidikan seperti itu disebut dengan meunasah, dan di Sumatera Barat disebut dengan surau ${ }^{3}$.

Dibandingkan dengan lingkungan pendidikan parsial yang ditawarkan sistem pendidikan sekolah umum di Indonesia sekarang ini, Pondok pesantren mempunyai kultur yang unik. Karena keunikannya, Ponpes digolongkan ke dalam subkultur tersendiri dalam masyarakat

\footnotetext{
${ }^{1}$ Muhammad Hasan, "Inovasi Dan Modernisasi Pendidikan Pondok Pesantren," KARS A: Journal of Social and Islamic Culture 23, no. 2 (2015): 296-306.

2 Pradina Astuti, "PESANTREN TRADISIONAL, DEMOKRATISASI PENDIDIKAN DAN PENGEMBANGAN MASYARAKAT,” Lembaran Masyarakat 1, no. 1 (2015): 69-98.

${ }^{3}$ K H Abdurrahman Wahid, Menggerakean Tradisi; Esai-Esai Pesantren (LKIS PELANGI AKSARA, 2001).
} 
Indonesia ${ }^{45}$. Ribuan Ponpes yang tersebar di enam puluh delapan ribu desa, merupakan bukti tersendiri untuk menyatakannya sebagai sebuah subkultur. Keunikan ini pula pada gilirannya dapat menghasilkan nilai ekonomis yang sangat besar bila dikelola secara profesional ${ }^{6}$.

Pondok Pesantren memegang peranan kunci sebagi motivator, inovator, dan dinamisator masyarakat ${ }^{7}$. Hubungan interaksionis-kultural antara Pondok Pesantren dengan masyarakat menjadikan keberadaan dan kehadiran institusi pesantren dalam perubahan dan pemberdayaan masyarakat menjadi semakin kuat ${ }^{8}$. Namun demikian, harus diakui belum semua potensi besar yang dimiliki Pondok Pesantren tersebut terkait dengan kontribusi pesantren dalam pemecahan masalah-masalah sosial ekonomi umat.

Pondok pesantren, kenyatannya adalah lembaga potensial untuk bergerak ke arah ekonomi berbasis rakyat, sebagaimana kekuatan yang dimilikinya. Jika Ponpes hanya menjadi penonton di era yang akan datang, maka lembaga-lembaga ekonomi mikro lain boleh jadi bergerak ke arah kemajuan ${ }^{9}$. Oleh karena itu, kiranya diperlukan analisis yang cermat untuk melakukan penguatan kelembagaan ekonomi ini, agar tidak salah melangkah.

Sasaran akhir dari pemberdayaan ekonomi Pondok Pesantren adalah kemandirian pesantren ${ }^{10}$. Selama ini Ponpes selalu dilabeli dengan nama lembaga pengedar proposal dana bantuan, baik pada institusi formal atau non formal. Labelling itu tentunya tidak mengenakkan. Pondok Pesantren akan terbebas dari anggapan itu kalau Pondok Pesantren menjadi lembaga yang kuat, terutama dalam sektor ekonomi ${ }^{11}$. Dengan sen-dirinya, tidak setiap ada kegiatan, apakah membangun gedung atau kegiatan lain, tidak selalu sibuk mengedarkan proposal kesanakemari.

\footnotetext{
${ }^{4}$ Irhamni Irhamni, "KEARIFAN LOKAL PENDIDIKAN PESANTREN TRADISIONAL DI JAWA: KAJIAN ATAS PRAKTEK PENERJEMAHAN JENGGOTAN,” ULUMUNA, 2011.

${ }^{5}$ Muhajir, "Pesantren Sebagai Instiusi," Jurnal Saintifika Islamica (2014).

${ }^{6}$ Arief Subhan, Lembaga Pendidikan Islam Di Indonesia (Kencana, 2012).

${ }^{7}$ Kedungkandang Malang and Siti Saroh, "PENGEMBANGAN MODEL PENDIDIKAN KEWIRAUSAHAAN DALAM MENINGKATKAN SKILL SANTRI; Kasus Di Ponpes Alhayatul Islamiyah,” SUSUNAN DEW AN PENYUNTING 6 (n.d.): 51.

8 Tirta Rahayu Ningsih, "PEMBERDAYAAN EKONOMI PESANTREN MELALUI PENGEMBANGAN SUMBER DAYA LOKAL," Lembaran Masyarakat: Jurnal Pengembangan Masyarakat Islam 3, no. 1 (2017): 57-78.

${ }^{9}$ Muhammad Jamaluddin, "Metamorfosis Pesantren Di Era Globalisasi," KARS A: Jurnal Sosial dan Budaya Keislaman (2012).

${ }^{10}$ Rizal Muttaqin, "Kemandirian Dan Pemberdayaan Ekonomi Berbasis Pesantren (Studi Atas Peran Pondok Pesantren Al-Ittifaq Kecamatan Rancabali Kabupaten Bandung Terhadap Kemandirian Eknomi Santri Dan Pemberdayaan Ekonomi Masyarakat Sekitarnya)," JESI (Jurnal Ekonomi Syariah Indonesia) 1, no. 2 (2016): 65-94.

11 Ahmad Rofiq, Pemberdayaan Pesantren: Menuju Kemandirian Dan Profesionalisme Santri Dengen Metode Daurah Kebudayaan (PT LKiS Pelangi Aksara, 2005).
} 
Pondok Pesantren sebagai sebuah "institusi budaya" yang lahir atas prakarsa dan inisiatif (tokoh) masyarakat dan bersifat otonom, sejak awal berdirinya merupakan potensi strategis yang ada di tengah kehidupan masyarakat ${ }^{12}$. Kendati kebanyakan pesantren memposisikan dirinya (hanya) sebagai institusi pendidikan dan keagamaan, namun sejak tahun 1970-an beberapa pesantren telah berupaya melakukan reposisi dalam menyikapi berbagai persoalan masyarakat, seperti ekonomi, sosial, dan politik. Berikut ini unsur-unsur yang diberdayakan di dalam lingkungan Pondok Pesantren.

Potensi ekonomi yang melekat pada Pondok Pesantren adalah santri, atau murid atau siswa. Analisis potensi diri ini harus dipahami, bahwa para santri tersebut sering mempunyai potensi/bakat bawaan, seperti kemampuan membaca al-Qur'an, kaligrafi, pertukangan, dan sebagainya. Bakat bawaan ini sudah seharusnya selalu dipupuk dan dikembangkan. Karena itulah, ada baiknya bila dalam Pondok Pesantren diterapkan penelusuran potensi/bakat dan minat santri, kemudian dibina dan dilatih.

Dengan demikian, dalam Pondok Pesantren tersebut perlu juga dikembangkan Wadah Apresiasi dan Pengambanan Lifeskill Santri, wadah semacam ini, mungkin sudah ada di beberapa Pondok Pesantren, tinggal bagaimana mengaturnya supaya produktif. Perlu juga ditambahkan, penggalian potensi diri santri-murid ini merambah pada potensi-potensi, semisal politisi, advokasi, jurnalistik, dan seterusnya. Karenanya, untuk ke depan wajah Pondok Pesantren menjadi semakin kaya ragam dan warna.

Apabila ketiga pilar utama ini terpenuhi, Pondok Pesantren telah memenuhi tiga fungsi utamanya, yaitu Pertama, sebagai pusat pengkaderan pemikir-pemikir agama (center of excellence). Kedua, sebagai lembaga yang mencetak sumber daya manusia (human resource). Ketiga, sebagai lembaga yang melakukan pemberdayaan pada masyarakat (agent of development $)^{13}$

Pondok Pesantren yang didiami oleh santri yang jumlahnya cukup banyak merupakan konsumen yang positif dan didukung oleh masyarakat sekitarnya ${ }^{14}$. Artinya, santri dan masyarakat sekeliling pada dasarnya adalah konsumen yang kebutuhannya dapat dicukupi secara

\footnotetext{
12 M Syaifuddien Zuhriy, "Budaya Pesantren Dan Pendidikan Karakter Pada Pondok Pesantren Salaf," Walisongo: Jurnal Penelitian Sosial Keagamaan 19, no. 2 (2011): 287-310.

${ }^{13}$ Keluarga Brooke, Sejarah Pemerintahan, and Keluarga Brooke, "Tokoh Ulama Di Sarawak Dan Peranannya Terhadap Kelangsungan Islam,” Prosiding Nadwah Ulama Nusantara (NUN) IV: Ulama Pemacu Transformasi Negara, no. November (2011): 25-26.

${ }^{14}$ Muhammad Fahri and Ahmad Sobari, "PEMBERDAYAAN KEMANDIRIAN EKONOMI BERBASIS PESANTREN MELALUI PROGRAM SANTRIPREUNER,” PROSIDING LPPM UIKA BOGOR (2017): 17-26.
} 
ekonomi oleh pesantren itu sendiri. Jadi, pesantren hakikatnya bisa mandiri untuk menjadi pusat kelembagaan ekonomi, bagi warganya di dalam pesantren dan di luar pesantren.

Santripreneur memiliki makna santri (orang yang menuntut ilmu di pesantren) yang mempunyai usaha sendiri, santri yang berani membuka kegiatan produktif yang mandiri ${ }^{15}$. Dapat juga diartikan sebagai seorang santri yang berani mengambil risiko untuk menjalankan usaha sendiri dengan memanfaatkan peluang-peluang untuk menciptakan usaha baru atau dengan pendekatan yang inovatif sehingga usaha yang dikelola berkembang menjadi besar dan mandiri dalam menghadapi tantangan-tantangan persaingan. Perdebatan yang sangat klasik adalah perdebatan mengenai apakah wirausahawan itu dilahirkan (is borned) yang menyebabkan seseorang mempunyai bakat lahiriah untuk menjadi wirausahawan, atau sebaliknya wirausahawan itu dibentuk atau dicetak (is made). Sebagian pakar berpendapat bahwa wirausahawan itu dilahirkan, sebagian pendapat mengatakan bahwa wirausahawan itu dapat dibentuk dengan berbagai contoh dan argumentasinya. Misalnya A tidak mengenyam pendidikan tinggi tetapi kini dia menjadi pengusaha besar tingkat nasional. Dilain pihak kini banyak pemimpin/ pemilik perusahaan yang berpendidikan tinggi tetapi reputasinya belum melebihi A tersebut. Pendapat lain adalah wirausahawan itu dapat dibentuk melalui suatu pendidikan atau pelatihan kewirausahaan ${ }^{16}$.

Dengan demikian, yang dimaksud dengan pendidikan kewirausahaan santri yaitu usaha sadar dan terencana yang dilaksanakan oleh pondok pesantren dalam meningkatkan kemandirian santri. Sehingga diharapkan ke depan, para santri memiliki bekal dalam merintis usaha.

\section{DAMPINGAN}

Secara umum, Pondok Pesantren Putra Miftahul Mubtadiin yang menjadi sasaran program kegiatan adalah pondok pesantren yang menampung para santri yang yatim piatu, fakir dan miskin. Dalam pelaksanaan kegiatan pendidikannya, banyak dispensasi dan keringan yang diberikan kepada santri, sehingga kegiatan dan semua program pembiayaannya banyak dilaksanakan subsidi silang.

Beberapa pertimbangan dan faktor utama pemilihan Pondok Pesantren Miftahul Mubtadiin Krempyang Tanjunganom Nganjuk adalah :

${ }^{15}$ Siti Robiah Adawiyah, "PENDIDIKAN KEWIRAUSAHAAN DI PONDOK PESANTREN SIROJUL HUDA," Comm-Edu (Community Education Journal) 1, no. 2 (2018): 81-87.

${ }^{16}$ Dewi Laila Hilyatin, "Pemberdayaan Kewirausahaan Santri Berbasis Madrasah Santripreneur Di Pondok Pesantren Darussalam,” Al-Amwal: Jurnal Ekonomi dan Perbankan Syariah 7, no. 2 (2016). 
1. Jumlah santri yang lebih dari 1500 (seribu lima ratus), berasal dari berbagai daerah, memiliki potensi dan kemampuan beragam.

2. Rata-rata lebih dari 100 santri setiap tahun lulus yang akan mengabdikan ilmunya kepada masyarakat dan membutuhkan ketrampilan dan kemampuan untuk bekal ekonomi dan membangun masyarakat.

3. Rata-rata lebih dari 100 santri baru mendaftar ke pondok pesantren, merupakan potensi besar untuk mengembangkan potensi ekonomi pondok pesantren.

4. Letak pondok yang berada dekat dengan pusat perbelanjaan (pasar, swalayan dll), potensi pengembangan ekonomi

5. Letak pondok pesantren yang berada di pedesaan dan dekat dengan pertanian yang menghasilkan bahan-bahan produksi, kedelai, jagung, padi dll.

6. Pondok pesantren memiliki lahan yang cukup luas, potensial untuk pengembangan produksi dan usaha perekonomian.

\section{METODE}

Pendekatan yang digunakan adalah kualitatif dengan metode deskriptif analitik. Penelitian ini didasarkan pada paradigma positivistik dengan metode kualitatif ${ }^{17}$. Pemilihan metode ini dipandang tepat guna memahami cara-cara atau pola-pola hidup suatu masyarakat yang memiliki tujuan-tujuan sendiri dan emosi, serta rencana-rencana dalam mengembangkan sebuah budaya bagi masyarakatnya ${ }^{18}$. Dengan melakukan penyelidikan secara kualitatif, peneliti mendekati partisipan yang diteliti dan mengembangkan pemahaman tentang apa yang terjadi di lingkungan mereka. Obyek penelitian selanjutnya dieksplorasi dan dipahami sebagai realitas alamiah. Penelitian ditujukan pada Pondok Pesantren Miftahul Mubtadiin Krempyang Tanjunganom Nganjuk, dengan jumlah santri 1500 dari berbagai daerah. Pengumpulan data menggunakan teknik observasi dan wawancara mendalam terhadap subjek penelitian. Penelitian dilakukan selama 12 bulan. Mulai dari bulan Maret 2017 sampai dengan Maret 2018.

\section{HASIL DAN DISKUSI}

Kata entrepreneurship pada mulanya sering diterjemahkan dengan kata kewiraswastaan, akhir-akhir ini diterjemahkan dengan kata kewirausahaan. Entrepreneur berasal dari bahasa Perancis yaitu entreprendre yang artinya memulai atau melaksanakan. Wiraswasta/wirausaha

\footnotetext{
17 Djam Satori, “An Dan Aan Komariah. 2010,” Metodologi Penelitian Kualitatif (n.d.).

${ }^{18}$ Robin Whittemore and Kathleen Knafl, “The Integrative Review: Updated Methodology,” Journal of advanced nursing 52, no. 5 (2005): 546-553.
} 
berasal ari kata: Wira: utama, gagah berani, luhur; swa: sendiri; sta: berdiri; usaha: kegiatan produktif. Dari asal kata tersebut, wiraswasta pada mulanya ditujukan pada orang-orang yang dapat berdiri sendiri.

Di Indonesia kata wiraswasta diartikan sebagai orang-orang yang tidak bekerja pada sector pemerintah yaitu; para pedagang, pengusaha, dan orang-orang yang bekerja di perusahaan swasta, sedangkan wirausahawan adalah orang-orang yang mempunyai usaha sendiri. Wirausahawan adalah orang yang berani membuka kegiatan produktif yang mandiri ${ }^{19}$.

Membahas masalah santripreneur sebenarnya tidak terlepas dari istilah enterpreneur itu sendiri karena santripreneur merupakan kependekan dari kata santri dan enterpreneur. Tidak ada makna baku untuk kata ini, karena jika ditelusuri dalam beberapa kamus bahasa Indonesia maupun bahasa asing tidak ditemukan makna kata tersebut.

Santripreneur memiliki makna santri (orang yang menuntut ilmu di pesantren) yang mempunyai usaha sendiri, santri yang berani membuka kegiatan produktif yang mandiri. Dapat juga diartikan sebagai seorang santri yang berani mengambil risiko untuk menjalankan usaha sendiri dengan memanfaatkan peluang-peluang untuk menciptakan usaha baru atau dengan pendekatan yang inovatif sehingga usaha yang dikelola berkembang menjadi besar dan mandiri dalam menghadapi tantangan- tantangan persaingan ${ }^{20}$.

1. Sejarah Singkat

Pondok Pesantren Miftahul Mubtadiin berkedudukan di Jl. KH. Wahid Hasyim 126 Krempyang Kel. Tanjunganom Kec. Tanjunganom Kab. Nganjuk, didirikan oleh KH. M. Ghozali Manan pada tahun 1940. Beliau dilahirkan di Dsn. Bedrek Ds. Bedrek Kec. Grogol Kab. Kediri tahun 1912. Pada tahun 1938 beliau menikah dengan seorang putri yang bernama Siti Khodijah, putri dari KH. Abdul Fattah Krempyang Tanjunganom Nganjuk dan selanjutnya menetap di dusun Krempyang sampai akhir hayatnya.

Pada waktu itu keadaan penduduk lingkungan Krempyang sudah banyak yang memeluk agama Islam, akan tetapi belum begitu tampak syi'arnya, setelah kedatangan beliau barulah syi'ar agama Islam di dusun ini mulai tampak dan semakin berkembang dengan pesat dan selanjutnya beliau berhasil mendirikan sebuah pondok pesantren yang tergolong sangat sederhana.

\footnotetext{
19 Titin Nurhidayati, "Inovasi Pembelajaran PAI Berbasis Multiple Intelligences," Jurnal Pendidikan Agama Islam (Journal of Islamic Education Studies) 3, no. 1 (2016): 23-56.

${ }^{20}$ Muhammad Anggung Manumanoso Prasetyo, "Manajemen Unit Usaha Pesantren," HIKMAH: Jurnal Pendidikan Islam (2017).
} 
Pesantren ini bermula dari sebuah mushola yang dikelola oleh KH. Abdul Fattah mertua KH. M. Ghozali Manan. Dengan berbekal ilmu yang di pelajari di pondok pesantren Mangunsari Nganjuk, Mojosari Nganjuk, Lirboyo Kediri dan di pondok pesantren Jampes Kediri, KH. Moh. Ghozali Manan bermaksud untuk mengembangkan Islam melalui sistem pondok pesantren. Untuk mewujudkan maksud tersebut, beliau merintis pondok pesantren dengan sistem belajar mengajar secara tradisional (ala pesantren kuno). Pada periode awal ini, ruang belajar yang digunakan sangat sederhana. Seiring dengan berjalannya waktu, musholla yang dulu dikelola oleh KH. Abdul Fattah dan kemudian diteruskan oleh KH. M. Ghozali Manan sekarang telah menjadi masjid yang sampai saat ini tetap lestari untuk kegiatan peribadatan para penduduk sekitar dan para santri.

Kemudian pada tahun 1942 didirikan pula sebuah Madrasah Ibtidaiyah (MI), dilanjutkan pada tahun 1952 beliau mendirikan lembaga pendidikan setingkat Madrasah Tsanawiyah (MTs), hingga pada akhirnya didirikan pula Madrasah Aliyah (MA) pada tahun 1989.

Setelah beberapa tahun lamanya, Pondok Pesantren yang dipimpin oleh KH. M. Ghozali Manan ini kemudian perlahan-lahan terus berkembang dan mengakar kuat sejalan dengan adanya dukungan dan peran serta santri yang telah dibina, dididik dan dibimbing dengan kesabaran dan ketulusan yang sungguh-sungguh. Hasil perjuangan beliau semakin tampak, terbukti dengan eksistensi Pondok Pesantren Miftahul Mubtadiin yang semakin diminati dan dipercaya oleh masyarakat umum baik dari wilayah pulau Jawa maupun luar Jawa.

Setelah beliau wafat (tahun 1990), Pondok Pesantren Miftahul Mubtadiin diasuh oleh putraputra beliau yaitu KH. Moh. Ridlwan Syaibani, KH. Moh. Hamam Ghozali dan Agus Nur Salim Ghozali. Pada periode inilah kepengasuhan santri mulai dipisah antara putra dan putri, baik secara kepemimpinan maupun secara manajemen.

Namun demikian, keberadaanya tetap menaungi semua unit pendidikan yang ada. Pada periode ini, perkembangan pondok pesantrenpun tampak semakin pesat dan mengalami kemajuan yang cukup signifikan, unit pendidikan yang sudah ada tetap berkembang dengan pesat.

Pada tahun 2002, berdasarkan hasil musyawarah dari bani Almarhum KH. Moh. Ghozali Manan, dihasilkan rumusan pemilahan atas kewenangan, kepemimpinan dan manajemen pondok pesantren. Dari sinilah lahir perubahan dari Pondok Pesantren Miftahul Mubtadiin menjadi Pondok Pesantren Putra Miftahul Mubtadiin, yang diasuh oleh KH. Moh. Ridlwan Syaibani dan Pondok Pesantren Putri Miftahul Mubtadiin diasuh oleh KH. Moh. Hamam Ghozali dan Agus Nursalim Ghozali. Meskipun demikian, keberadaan unit-unit pendidikan 
yang ada tetap berada dalam kepengasuhan unit-unit yang ada tetap dalam wewenang semua pengasuh.

Pada perkembangan selanjutnya, unit-unit pendidikan juga bertambah lagi dengan lahirnya Forum Kajian Khusus Kitab Kuning (FK4) sebagai wadah dari santri-santri purna Aliyah dan Madrasah Aliyah Mu'adalah (Madrasatul 'Ulya PP. Miftahul Mubtadiin), serta Sekolah Tinggi Agama Islam Darussalam (STAIDA).

Sebagaimana data statistik yang ada, jumlah santri Pondok Pesantren Putra Miftahul Mubtadiin Krempyang adalah :

\begin{tabular}{|c|l|c|}
\hline No & \multicolumn{1}{|c|}{ Jenis Santri } & Jumlah \\
\hline 1 & Mondok/Bermukim & 1452 \\
\hline 2 & Nduduk/Pulang-Pergi & 910 \\
\hline & JUMLAH & $\mathbf{2 3 6 2}$ \\
\hline
\end{tabular}

Tabel 1 : Jumlah Santri di Pondok Pesantren

Dalam rangka untuk mengikuti perkembangan kemajuan zaman, serta melaksanakan undang-undang serta peraturan yang berlaku, maka secara kelembagaan formal unit-unit yang ada didaftarkan sesuai aturan yang berlaku. Secara rinci, perkembangan organisasi kelembagaan yang ada adalah sebagai berikut:

a. Struktur pengurus yang tersusun secara baik

b. Dibentuk seksi khusus perekonomian pondok, meliputi

1) Usaha Peternakan sapi

2) Usaha Tahu

3) Usaha Pertanian

c. Santri dilibatkan dalam kegiatan ekonomi pondok

2. Usaha Ekonomi

Dengan jumlah santri yang lebih dari 1500 (seribu lima ratus), dan penghasilan ekonomi pondok yang demikian, maka secara matematik perlu adanya penambahan dan subsidi untuk kegiatan operasional.

Langkah kongkrit dalam mengembangkan potensi dan memenuhi kebutuhan operasional dan pembangunan pondok, adalah melalui program pengembangan ekonomi pondok pesantren yang berbasis pendampingan pada santri melalui pemberian pelatihan lifeskill dan modal usaha.

Adapun program yang dilaksanakan diantaranya :

\section{a. Program Utama}

Volume 2, Number 2, November 2018| 228 
Program utama adalah merupakan program kegiatan yang diberikan kepada santri secara umum tanpa membedakan jenis kelamin. Adapun program utama adalah sebagai berikut :

\begin{tabular}{|c|c|c|c|l|}
\hline No & Jenis Program & Metode & \multicolumn{1}{|c|}{ Sasaran } & \multicolumn{1}{|c|}{ Hasil/Output } \\
\hline 1 & 2 & 3 & 4 & \multicolumn{1}{|c|}{5} \\
\hline 1 & Usaha Tahu & Pelatihan & $\begin{array}{c}\text { Santri yang } \\
\text { akan lulus }\end{array}$ & $\begin{array}{l}\text { Santri mampu memproduksi, } \\
\text { memasarkan, memanaj } \\
\text { produksi }\end{array}$ \\
\hline 2 & Usaha Tempe & Pelatihan & $\begin{array}{l}\text { Santri yang } \\
\text { akan lulus }\end{array}$ & $\begin{array}{l}\text { Santri mampu memproduksi, } \\
\text { memasarkan, } \\
\text { produksi }\end{array}$ \\
\hline
\end{tabular}

b. Program Pendukung

\begin{tabular}{|c|l|c|c|l|}
\hline No & \multicolumn{1}{|c|}{ Jenis Program } & Metode & Sasaran & \multicolumn{1}{|c|}{ Hasil/Output } \\
\hline 1 & 2 & 3 & 4 & 5 \\
\hline 1 & $\begin{array}{l}\text { Pengadaan Mesin } \\
\text { Penggiling Kedelai }\end{array}$ & Hibah & Pondok & $\begin{array}{l}\text { Pondok Memiliki Mesin } \\
\text { Penggiling Kedelai }\end{array}$ \\
\hline 2 & $\begin{array}{l}\text { Pengadaan Kendaraan } \\
\text { Operasional Usaha }\end{array}$ & Hibah & Pondok & $\begin{array}{l}\text { Pondok memiliki Kendaraan } \\
\text { Operasional Usaha }\end{array}$ \\
\hline 3 & Pemberian Modal & Hibah & Pondok & $\begin{array}{l}\text { Pondok Memiliki Tambahan } \\
\text { Modal Pengembangan Usaha }\end{array}$ \\
\hline 4 & $\begin{array}{l}\text { Pemberian Peralatan } \\
\text { Pemasaran }\end{array}$ & Hibah & Pondok & $\begin{array}{l}\text { Pondok Memiliki Peralatan } \\
\text { Pemasaran }\end{array}$ \\
\hline
\end{tabular}

Secara umum, manfaat yang menjadi target dari kegiatan ini adalah para santri memiliki ketrampilan sebagai bekal setelah mereka lulus dari pondok pesantren. Secara rinci, hasil yang ingin dicapai adalah sebagai berikut:

1. Santri memiliki ketrampilan membuat tahu dan tempe

2. Santri memiliki usaha produksi tahu dan tempe

3. Santri memiliki hasil usaha tahu dan tempe serta mampu memanfaatkan baik secara pribadi, pondok pesantren dan masyarakat

4. Santri memiliki kemampuan usaha tahu dan tempe untuk berbagi ilmu dan ketrampilannya kepada santri yang lainnya 
Santri mampu mensosialisasikan ketrampilan dan ilmu usaha tahu dan tempe bagi pemberdayaan ekonomi masyarakat

Pihak-pihak yang terlibat (stakeholders) dan menjelaskan bagaimana bentuk keterlibatannya dalam konteks pengabdian untuk mencapai kondisi dampingan yang diharapkan.

1. Dosen STAI Darussalam Krempyang Tanjunganom Nganjuk
a. Tenaga
b. Pemikiran

2. LP3M (Lembaga Pengkajian, Penelitian dan Pengabdian kepada Masyarakat) STAI Darussalam Krempyang Tanjunganom Nganjuk
a. Pendampingan
b. Pelatihan

3. Pengasuh Pondok Sasaran Program
a. Tenaga
b. Sarana-prasarana

4. Kementerian Agama Kabupaten Nganjuk
a. Tenaga pembinaan
b. Pendanaan

5. Pemerintah Daerah Kabupaten Nganjuk
a. Pendanaan

6. Pihak Swasta/pengusaha
a. Kerjasama Permodalan
b. Kerjasama Pelatihan

\section{KESIMPULAN}

Pondok Pesantren sebagai sebuah "institusi budaya" yang lahir atas prakarsa dan inisiatif (tokoh) masyarakat dan bersifat otonom, sejak awal berdirinya merupakan potensi strategis yang ada di tengah kehidupan masyarakat. Kendati kebanyakan pesantren memposisikan dirinya (hanya) sebagai institusi pendidikan dan keagamaan, namun sejak tahun 1970-an beberapa pesantren telah berupaya melakukan reposisi dalam menyikapi berbagai persoalan masyarakat, seperti ekonomi, sosial, dan politik. Program santriprenenurship merupakan contoh kongrit dalam pemberdayaan santri dalam wirausaha demi meningkatkan kemandirian santri. 
SARAN

Kepada Pemerintah, agar mendukung gerakan santripreneur di pesantren. Karena pesantren merupakan salah satu asset bangsa yang harus dilestarikan. Dalam hal ini adalah peningkatan kemandirian ekonomi dalam program santripreneur.

\section{DAFTAR PUSTAKA}

Adawiyah, Siti Robiah. "PENDIDIKAN KEWIRAUSAHAAN DI PONDOK PESANTREN SIROJUL HUDA." Comm-Edu (Community Education Journal) 1, no. 2 (2018): 81-87.

Astuti, Pradina. "PESANTREN TRADISIONAL, DEMOKRATISASI PENDIDIKAN DAN PENGEMBANGAN MASYARAKAT.” Lembaran Masyarakat 1, no. 1 (2015): 69_ 98.

Brooke, Keluarga, Sejarah Pemerintahan, and Keluarga Brooke. "Tokoh Ulama Di Sarawak Dan Peranannya Terhadap Kelangsungan Islam." Prosiding Nadwah Ulama Nusantara (NUN) IV: Ulama Pemacu Transformasi Negara, no. November (2011): 25-26.

Fahri, Muhammad, and Ahmad Sobari. "PEMBERDAYAAN KEMANDIRIAN EKONOMI BERBASIS PESANTREN MELALUI PROGRAM SANTRIPREUNER.” PROSIDING LPPM UIKA BOGOR (2017): 17-26.

Hasan, Muhammad. "Inovasi Dan Modernisasi Pendidikan Pondok Pesantren." KARSA: Journal of Social and Islamic Culture 23, no. 2 (2015): 296-306.

Hilyatin, Dewi Laila. "Pemberdayaan Kewirausahaan Santri Berbasis Madrasah Santripreneur Di Pondok Pesantren Darussalam." Al-Amwal: Jumal Ekonomi dan Perbankan Syari'ah 7, no. 2 (2016).

Irhamni, Irhamni. "KEARIFAN LOKAL PENDIDIKAN PESANTREN TRADISIONAL DI JAWA: KAJIAN ATAS PRAKTEK PENERJEMAHAN JENGGOTAN.” ULUMUNA, 2011.

Jamaluddin, Muhammad. "Metamorfosis Pesantren Di Era Globalisasi." KARSA: Jurnal Sosial dan Budaya Keislaman (2012).

Malang, Kedungkandang, and Siti Saroh. "PENGEMBANGAN MODEL PENDIDIKAN KEWIRAUSAHAAN DALAM MENINGKATKAN SKILL SANTRI; Kasus Di Ponpes Alhayatul Islamiyah.” SUSUNAN DEW AN PENYUNTING 6 (n.d.): 51.

Muhajir. "Pesantren Sebagai Instiusi." Jurnal Saintifika Islamica (2014).

Muttaqin, Rizal. "Kemandirian Dan Pemberdayaan Ekonomi Berbasis Pesantren (Studi Atas Peran Pondok Pesantren Al-Ittifaq Kecamatan Rancabali Kabupaten Bandung Terhadap Kemandirian Eknomi Santri Dan Pemberdayaan Ekonomi Masyarakat Sekitarnya)." JESI (Jurnal Ekonomi Syariah Indonesia) 1, no. 2 (2016): 65-94.

Ningsih, Tirta Rahayu. "PEMBERDAYAAN EKONOMI PESANTREN MELALUI PENGEMBANGAN SUMBER DAYA LOKAL." Lembaran Masyarakat: Jurnal Pengembangan Masyarakat Islam 3, no. 1 (2017): 57-78.

Nurhidayati, Titin. "Inovasi Pembelajaran PAI Berbasis Multiple Intelligences." Jurnal Pendidikan Agama Islam (Journal of Islamic Education Studies) 3, no. 1 (2016): 23-56.

Prasetyo, Muhammad Anggung Manumanoso. "Manajemen Unit Usaha Pesantren." HIKM AH: Jurnal Pendidikan Islam (2017).

Rofiq, Ahmad. Pemberdayaan Pesantren: Meniju Kemandirian Dan Profesionalisme Santri Dengen Metode Daurah Kebudayaan. PT LKiS Pelangi Aksara, 2005.

Satori, Djam. "An Dan Aan Komariah. 2010.” Metodologi Penelitian Kualitatif (n.d.).

Subhan, Arief. Lembaga Pendidikan Islam Di Indonesia. Kencana, 2012. 


\section{ENGAGEMENT}

Jurnal Pengabdian Kepada Masyarakat

ISSN : 2579-8375 (Print)

ISSN : 2579-8391 (Online)
This work is licensed under a Creative Commons Attribution-ShareAlike 4.0 International License.

Wahid, K H Abdurrahman. Menggerakkan Tradisi; Esai-Esai Pesantren. LKIS PELANGI AKSARA, 2001.

Whittemore, Robin, and Kathleen Knafl. "The Integrative Review: Updated Methodology." Journal of advanced nursing 52, no. 5 (2005): 546-553.

Zuhriy, M Syaifuddien. "Budaya Pesantren Dan Pendidikan Karakter Pada Pondok Pesantren Salaf." Walisongo: Jumal Penelitian Sosial Keagamaan 19, no. 2 (2011): 287-310. 